\title{
MEMASYARATKAN SHOLAWAT NARIYAH DI BUMI NUSANTARA
}

\author{
${ }^{1}$ Ahmad Farhan Holidi \& ${ }^{2}$ Miftahus Surur \\ Email: ${ }^{1}$ farhankholidi5@gmail.com $\&{ }^{2}$ sururmiftah@ gmail.com \\ ${ }^{1}$ Sekolah Tinggi Ilmu Al Qur'an Wali Songo \\ ${ }^{2}$ STKIP PGRI Situbondo
}

\begin{abstract}
The tradition of reading the Nariyah prayer individually and in congregation has taken root in the midst of the community especially in Situbondo district, in every corner of the city and remote villages even though every day is not empty from reciting the 4444 shalawat nariyah individually and in congregation, so that Situbondo district is the term "BUMI SHALAWAT NARIYAH". At first Jam'iyah this prayer was commanded by KH Ahmad Sufyan Miftahul Arifin (Situbondo) and KH Muhammed bin Imam Gunungsari (Madura) then continued by his students both namely KHR Moh Kholil As'ad Syamsul Arifin he was the son of KH As' ad the mediator in the formation of Jam'iyah Nahdhatul Ulama (NU) as well as the Indonesian National hero. And today the recitation of the Nariyah prayer has spread widely in various regions, in East Java, Bali, Kalimantan, DKI Jakarta, DIY Yogyakarta to foreign countries such as Malaysia and Singapore all thanks to the help of Allah SWT with the hope that Allah will flow to us all drop by drop from the ocean of God's grace which was bestowed upon the Prophet Muhammad.

Keyword: Sholawat Nariyah, Bumi Nusantara
\end{abstract}

\section{A. Pendahuluan}

Makkah adalah tanah suci bagi umat Islam, namun pada mulanya sebelum terutusnya nabi Muhammad, Makkah adalah sebuah daerah yang gersang, bukan hanya gersang dalam konteks lahiriyah saja, lebih dari itu gersang dalam akidah, gersang dalam moral baik individu atau sosial, gersang akan rasa kemanusiaan. Lihatlah betapa tangis dan rintihan orang yang lemah pada saat itu seakan tanpa akhir, lihatlah betapa congkaknya mereka-mereka yang berkuasa tertawaria melihat deraian air mata si lemah, perhatikanlah bagaimana nasib para wanita yang tak dihargai samasekali, seakan mereka di lahirkan hanya untuk melahirkan bahkan lebih kejam dari pada itu, para wanita dianggap hanyalah sebuah benalu yang menjadi beban sehingga akhirnya mereka dianggap tidak berhak untuk hidup. Bahasa kongkritnya, yang kaya digjaya yang miskin hina, yang kuat berkuasa yang lemah nista.

Namun di tengah-tengah awan gelap yang menyelimuti Makkah pada saat itu, terdapat sebuah keluarga suci laksana lentera di tengah gulita malam, beliaulah Sayyid Abdullah dan Sayyidah Aminah yang pada akhirnya melahirkan seorang putra yang 
menjadi utusan Allah kepada seluruh semesta alam, sang revolusioner dunia yang telah membawa mereka dari dunia Jahiliyah menuju dunia Hidayah beliaulah nabi Muhammad SAW.

Sebagaimana telah kita ketahui dan kita yakini bahwa nabi Muhammad adalah utusan Allah dan manusia terbaik, tepatnya makhluq yang paling dicintai oleh Allah SWT. Beliau adalah makhluq yang dihiasi dengan keindahan baik keindahan jasmani terlebih lagi keindahan rohani.

Mari kita perhatikan secara seksama pengalaman Sayidina Jabir ibnu Samurah RA beliau berkata: "Pernah pada suatu malam aku memandang Rasulullah dan rembulan, menurutku Rasulullah lebih indah dari pada Rembulan”.

Begitu banyak sanjung madah para sahabat Rasulullah untuk mengibaratkan sekelumit dari kepribadian Rasulullah SAW, namun kami tidak bermaksud untuk menuliskan semua ungkapan sahabat kepada Rasulullah itu, karena kami yakin seandainya laut di jadikan tinta dan pepohonan di jadikan pena, tidak akan mampu untuk mengibaratkan secara tuntas bagaimana sesosok Insan Al-kamil ini, sangatlah cukup pujian Allah SWT di dalam firmannya:

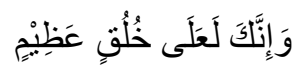

Artinya: Sesungguhnya engkau(Nabi Muhammad) benar-benar berada di atas akhlaq yang agung.

Nabi Muhammad adalah makhluq Allah yang paling sempurna dan paling dicintai oleh Allah sehingga Allah berfirman di dalam Al-qur'an:

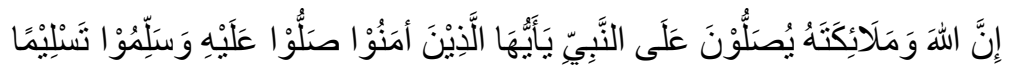

Artinya: Sesungguhnya Allah dan para Malaikat-Nya bershalawat atas Nabi, wahai orang-orang yang beriman bershalawat dan sampaikanlah salam kepadanya!.

Mari kita kaji bersama ayat diatas "sesungguhnya Allah dan Malaikat-Nya bershalawat" menurut Ibnu Abbas RA yang di kutip oleh Syekh Yusuf bin Ismail An- 
nabhani dalam kitab Afdhalus Shalawat, bahwa shalawat Allah atas Rasulullah adalah rahmat(kasih sayang) sedangkan shalawat Malaikat atas Rasulullah adalah Istighfar. ${ }^{1}$

Abu Aliyah berkata: Shalawat Allah adalah pujian Allah kepada Rasulullah dan shalawat Malaikat adalah do'a. ${ }^{2}$

Kemudian setelah itu Allah mengajak orang-orang yang beriman supaya bergabung untuk bershalawat kepada Rasulullah dengan firman "wahai orang-orang yang beriman bershalawat dan sampaikanlah salam kepadanya!”.

Jika anda bertanya: "bukankah shalawat Allah dan para Malaikat sudah cukup untuk Rasulullah, lalu apa gunanya kita bershalawat untuk Rasulullah?" maka jawabannya: iya benar, shalawat Allah dan Para Malaikat untuk Rasulullah sudah lebih dari cukup, namun kalau diibaratkan shalawat Allah dan Malaikat yang telah dianugerahkan untuk Rasululah itu seperti sebuah wadah yang penuh dengan air, jika kita meminta kepada Allah untuk ditambah lagi ditambah lagi maka air itu akan meluap, nah inilah yang kita harapkan setetes demi setetes rahmat dan ampunan Allah yang telah dianugerahkan kepada Rasulullah akan mengalir kepada kita semua.

Shalawat kepada Rasulullah akan mendatangkan keutamaan keutamaan yang akan diberikan oleh Allah SWT, Rasulullah bersabda:

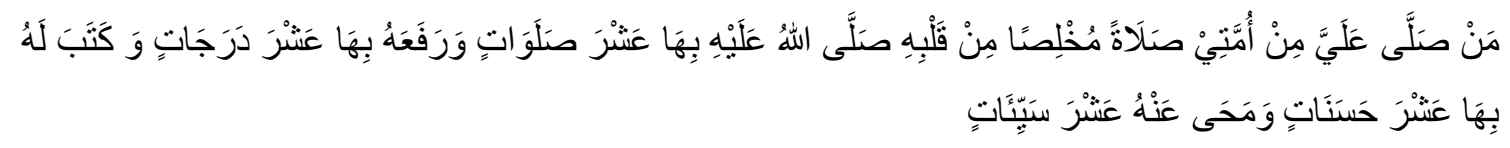

Artinya: barang siapa yang bershalwat kepadaku dari umatku satu kali dan ia ikhlas dari hatinya, maka Allah memberi shalawat kepadanya sepuluh shalawat, Allah mengangkat derajatnya sepuluh derajat, dan Allah menuliskan sepuluh amal kebaikan untuknya, serta Allah menghapus sepuluh kejelekan darinya. ${ }^{3}$

Shalawat secara garis besar ada dua macam yaitu shalawat yang diajarkan langsung oleh Rasulullah yang biasa kita kenal dengan sebutan shalwat Ibrahimiyah,

\footnotetext{
${ }^{1}$ Syekh Yusuf al-Nabhani, Afdhalu al-Shalawat Ala Sayyid al-Sadat, (Jakarta: Dar al-kutub Islamiyah, 2004), hal.11.

2 Ibid.

3 Ibid, hal. 25.
} 
dan shalwat yang di susun oleh para sahabat Rasulullah, para Tabiin dan para ulama lainnya. Salah satu dari jutaan shalawat itu adalah shalawat Nariyah.

Shalawat Nariyah juga populer dengan sebutan shalawat Tafrijiyah para Ulama banyak menyebutkan tentang keistimewaan shalawat ini salah satunya yaitu yang telah di sebutkan oleh Imam Al-qurthuby bahwa barang siapa yang mempunyai keinginan untuk memperoleh sesuatu yang agung atau terhindar dari bencana maka hendaklah bertawasul kepada Rasulullah kemudian membaca shalawat Tafrijiyah ini sebanyak 4444 kali, maka Allah akan mempermudah apa yang menjadi tujuannya sesuai dengan niatannya. ${ }^{4}$

Jika ditinjau dari segi sejarah, KH Muchtarul Arifin salah seorang penggerak shalawat Nariyah berkata, bahwa pernah pada suatu hari KH Sufyan Miftahul Arifin bercerita "Pada dahulu kala di negeri Maghrib dilanda sebuah paceklik yang berkepanjangan sehingga mayoritas masyarakat pada saat itu tidak bisa makan melainkan harus memakan barang yang haram, entah lewat mencuri merampok dan sebagainya, hal ini tentu sangat membuat gelisah Imam Al-qurthuby betapa tidak, beliau sebagai pewaris dari Rasulullah melihat keadaan masyarakat yang carut marut ditutupi oleh perkara-perkara haram yang disebabkan oleh paceklik yang berkepanjangan, baik paceklik ekonomi ataupun paceklik yang melanda akidah. Dalam kondisi itu Imam Alqurthuby didatangi oleh Rasulullah SAW dan menyuruhnya untuk menggerakkan shalawat Nariyah 4444. Imam Al-qurthuby pun melaksanakannya beliau mengajak masyarakat untuk membaca shalawat Nariyah, bahkan beliau menghadap kepada raja agar memerintahkan seluruh warga untuk membaca shalawat Nariyah. Selang beberapa lama bi idznillah Allah menghilangkan paceklik-paceklik itu, baik yang melanda ekonomi, keamanan lebih-lebih paceklik yang melanda rohani.

\section{B. Proses pembacaan shalawat Nariyah secara berjamaah}

Proses pembacaan shalawat Nariyah secara berjamaah yang terdapat di berbagai daerah dianjurkan untuk sama, tujuannya adalah supaya shalawat yang di baca itu sama, dengan maksud dan niatan yang sama pula. Proses dari pembacaan shalwat Nariyah ini

\footnotetext{
${ }^{4}$ Ibid hal.160.
} 
terbilang cukup sederhana yang tersusun sebagaimana berikut: langkah pertama masingmasing dari ketua jamaah memimpin para jamaahnya untuk menyampaikan niatanniatan dalam membaca shalawat Nariyah, yang mana niatannya tersusun sebagaimana berikut:

Dengan harapan agar Allah menambahkan keimanan dan kecintaan kita kepada Allah dan Rasulullah serta kepada orang-orang yang shaleh.

Dengan harapan agar Allah mempermudah kita dalam menerima sekaligus mengamalkan tuntunan-tuntunan Allah.

Dengan harapan kita diberikan husnul khawatim dalam setiap aspek kehidupan kita.

Dengan harapan semoga Negara Indonesia di jauhkan dari malapetaka dan menjadi tempat yang fiddunya hasanah yang menjadi tangga untuk memperoleh wafil akhirati hasanah.

Niat baik jamaah masing-masing dhahir batin dunia akhirat.

Setelah itu ketua kelompok tersebut memimpin para jamaah untuk bertawasul dengan membaca Al-fatihah untuk Rasulullah, para keluarga nabi, para sahabat nabi dan orangorang yang shaleh, selanjutnya membaca shalawat Nariyah sebanyak 4444 dengan gotong royong dan bersama-sama.

Dan dewasa ini, kumpulan-kumpulan pembacaan shalawat Nariyah telah menyebar di berbagai daerah khususnya di kabupaten Situbondo dan sekitarnya dengan harapan dan niatan yang sama.

Namun telah menjadi rumus pasti di dunia ini, jika ada siang pasti ada malam, jika ada manis pasti ada pahit, begitu pula jika ada pro sudah barang pasti akan ada kontra. Demikian pula yang berkembang di masyarakat, banyak yang menerima dengan baik dan simpatik terhadap shalawat Nariyah juga terdapat segolongan yang enggan terhadap shalwat Nariyah dengan alasan tertentu, bahkan juga terdapat segolongan yang secara ekstrime menganggap shalwat Nariyah bertentangan dengan Islam. Benarkah demikian? Mari kita ikuti pembahasan berikut!. 


\section{C.Pembahasan}

Di dalam tradisi pembacaan shalawat Nariyah ini terdapat beberapa poin penting yang harus kita perhatikan secara seksama jika kita bermaksud untuk mendapatkan benang merah atau kongklosi tepat dari kegiatan ini, Dan untuk mendapatkan kesimpulan yang objektif serta jernih kita harus mencermatinya dengan hati yang jernih pula, karena jika bisa kami ibaratkan hati itu laksana wadah, jika wadah yang kita siapkan adalah wadah yang bersih maka air jernih yang dituangkan kedalam wadah itu akan terlihat kejernihannya, namun jika wadah yang kita siapkan adalah wadah yang berdebu, maka sekalipun air jernih yang dituangkan akan terlihat kotor ketika berada di wadah tersebut. Semoga Allah senantiasa memberi hidayah kepada kita sekalian dan menjernihkan hati dan fikiran kita.

Poin poin penting di dalam sholawat Nariyah adalah sebagaimana berikut:

\section{Niat dan tujuan diadakannya kegiatan shalawat Nariyah.}

Sebagaimana yang telah kita ketahui bersama, bahwa setiap aspek kegiatan manusia baik secara lahiriyah atau batiniyah, secara duniawiyah atau ukhrawiyah tergantung bagaimana niat dan tujuan dari kegiatan tersebut. Maka dari itu di dalam kegiatan shalawat ini di tekankan untuk memiliki niat dan tujuan yang sama sebagaimana yang telah kami kemukakan di atas.

Jika kita cermati tujuan inti dari diadakannya kegiatan ini, bukan semata-mata untuk mengharapkan pahala saja dengan keutaman-keutamaan yang telah di jamin oleh Allah bagi orang yang membaca shalawat. Namun lebih dari pada itu, tujuan inti dari adanya kegiatan ini adalah pembangunan karakter perindividual dalam jiwa masyarakat. Betapa tidak, coba kita cermati niatan pertama dari kegiatan shalawat ini adalah dengan harapan agar Allah menambahkan keimanan dan kecintaan kita kepada Allah, Rasulullah, serta orang-orang yang shaleh, sedangkan keimanan dan cinta adalah dua power penting yang harus ada di dalam jiwa manusia. Rasulullah SAW bersabda:

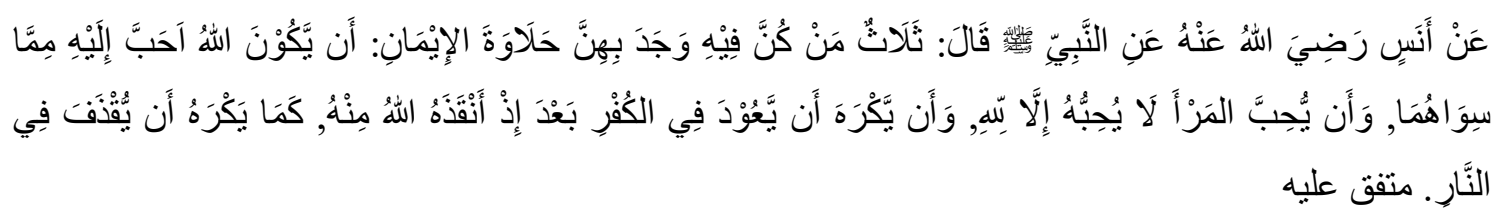


Artinya: Anas ra. Meriwayatkan dari Nabi saw. Bahwa beliau bersabda, "Ada tiga perkara, barangsiapa yang padanya ada tiga perkara itu ia akan mendapatkan manisnya keimanan; Allah dan Rasul-Nya paling dicintainya daripada yang lain; seseorang mencintai orang lain karena Allah; dan ia benci untuk kembali kepada kekafiran setelah Allah menyelamatkannya dari kekafiran sebagaimana ia benci jika dilemparkan ke dalam neraka.” (Muttafaq 'alaih) ${ }^{5}$

Sebagaimana hadits diatas telah nyata bagi kita, bagaimana peran dan manfaat kecintaan dalam jiwa manusia, boleh dikata keimanan dan kecintaan adalah dua pondasi atau dua power yang tidak boleh tidak harus ada di dalam jiwa manusia, dan keduanya adalah ruh bagi segala aspek kehidupan manusia dalam individual, beragama, berbangsa, dan bernegara.

Nah inilah tujuan pokok akan diadakannya kegiatan ini, sebagaimana telah kita ketahui dan kita rasakan bersama begaimana paradigma kemanusiaan dalam bangsa kita dewasa ini,betapa tindak criminalitas merajalela mulai dari anak kecil hingga dewasa, kuku tirani kedzaliman mencengkram erat melilit mereka yang tak berdaya, bukan hanya krisis ekonomi yang melanda lebih dari itu krisis kemanusiaan telah menggrogoti bangsa kita.

Hal inilah yang mendasari para kiyai khususnya KH Ahmad Sufyan dan KH Muhammad bin Imam sehingga menggerakkan tradisi pembacaan shalawat Nariyah 4444 secara berjamaah ini, untuk meninggikan Allah dalam jiwa manusia, sehingga dapat diaplikasikan dalam kehidupan individual, social bahkan berbangsa dan bernegara, sehingga agama tidak hanya hidup di dalam masjid saja, lebih dari pada itu agama harus hidup di dalam perdagangan, agama harus hidup di dalam pertanian, agama harus hidup di dalam perkantoran, bahkan agama harus hidup di dalam birokrasi kenegaraan.

Jika anda bertanya, "Di dalam niatan shalawat Nariyah mengapa masih mencantumkan "cinta terhadap orang shaleh?".

Jawabannya adalah, cinta terhadap orang shaleh sangat berperan penting dalam pembentukan karakter seorang manusia. Betapa tidak, setiap hari kita berinteraksi

\footnotetext{
${ }^{5}$ Imam al-Nawawi, Riyad al-Shalihin, (Surabaya: al-Haramain), hal.191
} 
dengan orang lain dengan latar belakang dan karakter yang beragam, dan pasti pergaulan itu sangat bereffect besar bagi kita. Maka kita sangat membutuhkan orang yang shaleh untuk menemani, memotivasi, dan mengajak kita mengarungi gurun luas kehidupan yang fana ini hingga kelak di alam abadi, dengan berada di bawah naungan cahaya ilahi. Rasulullah saw bersabda, "Seseorang itu tergantung agama sahabatnya, maka hendaklah kalian memperhatikan dengan siapa dia bersahabat!". Coba kita renungkan bagaimana para Sahabat Rasulullah? Beliau-beliau memperoleh pengakuan langsung dari Allah dengan firman-Nya, "Allah ridha kepada mereka, dan mereka ridha kepada Allah". Perhatikanlah! Dengan siapa beliau-beliau bersahabat? Mereka bersahabat dengan Sayyidul al-Shalihin wa al-Mursalin Nabi Muhammad saw. Coba kita perhatikan para Tabiin! Mereka mendapatkan derajat yang mulia di sisi Allah sebab bersahabat dengan siapa? Dengan para Sahabat Rasulullah lah mereka bersahabat. Demikian pula para Tabiit Tabiin dan para ulama dari berbagai generasi mereka mendapatkan kedudukan istimewa di sisi Allah, jalan terbesarnya adalah karena mereka bershuhbah dengan orang-orang yang mempunyai sanad rantai emas kepada Rasulullah SAW. Jika kita merenungkan hal ini, alangkah benar apa yang telah disampaikan oleh Ulama, "Demi Allah tidaklah beruntung orang yang beruntung kecuali bersama-sama orang yang beruntung”.

Renungkanlah! Betapa mulianya Nabi Yusuf as? Beliau bukan hanya orang yang shaleh tapi beliau adalah Nabi dan Rasul Allah SWT. Namun beliau masih mengharap kepada Allah untuk senantiasa dikumpulkan dengan orang-orang yang shaleh, sehingga doa beliau diabadikan di dalam al-Qur'an,

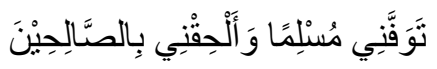

Artinya: "Wafatkanlah aku dalam keadaan Muslim dan gabungkanlah aku dengan orang-orang yang shaleh!”

Bahkan Nabi Ibrahim as juga memohon kepada Allah,

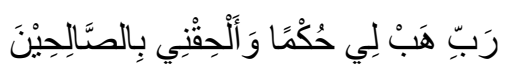

Artinya: "Wahai tuhanku, anugerahkanlah kepadaku hikmah, dan gabungkanlah aku dengan orang-orang yang shaleh!”. 


\section{Berdzikir secara berjamaah}

Dzikir secara etimology adalah mengingat atau menyebut. Sedangkan secara terminology adalah sebagaimana yang telah di sebutkan oleh Syekh Muhammad bin Ilan as-Syafii al-Asy'ari al-Makki dalam kitab Dalilu al-Falihin Li Thuruqi Riyadh alShalihin bahwa yang di maksud dzikir adalah mengucapkan lafadz-lafadz yang dapat mendatangkan rasa cinta dan sungguh-sungghuh kepada Allah, dan terkadang istilah dzikir digunakan sebagai ungkapan bagi setiap perkataan yang mendapatkan pahala dari Allah. $^{6}$

al-Hafidz berkata: "Bahwa yang dimaksud dengan dzikir adalah menekuni setiap amal yang diwajibkan atau dianjurkan oleh Allah swt. Simpelnya dzikir adalah mengingat Allah, karena Allah, dan mengharap Allah. ${ }^{7}$

Menurut Imam al-Nawawi dzikir ada yang diungkapkan dengan lisan ada juga dengan hati, namun yang paling utama adalah berdzikir dengan hati yang diungkapkan dengan lisan secara bersamaan, jika tidak bisa berdzikir dengan hati dan lisan secara bersamaan, maka yang paling utama adalah dzikir dengan hati. ${ }^{8}$

Dzikir sangat dianjurkan oleh Allah baik secara individu atau berjamaah, dzikir secara individu sangat jarang sekali kontra di dalam masalah ini, namun dzikir secara berjamaah masih ada orang-orang yang menganggap bahwa dzikir secara berjamaah ini tidak di benarkan di dalam Islam. Benarkah demikian?

Banyak sekali dalil-dalil hadits-hadits Rasulullah yang menjelaskan tentang keutamaan dzikir secara berjamaah, sebagaimana yang telah banyak di jelaskan oleh para ulama di dalam kitab-kitab dan buku-buku mereka salah satunya sebagaimana yang telah di jelaskan oleh KH Drs Ahmad Dimyati Badruzzaman M.A. di dalam bukunya Zikir Berjamaah Sunnah Atau Bid'ah namun kami tidak bermaksud untuk menyebutkan semua dalil itu secara detail, karena kami yakin bahwa orang yang beriman dan berhati jernih tidak membutuhkan banyak dalil untuk menerima, dan

6 Syekh Muhammad bin Ilan as-Syafii al-Asy'ari al-Makki, Dalilu al-Falihin Li Thuruqi Riyadh al-Shalihin, (Mesir: alMaktabah al-Taufiqiyah), hal. 176, juz. 4.

\footnotetext{
${ }^{7}$ Ibid.

${ }^{8}$ Imam Nawawi, al-Adzkar al-Nawawiyah, (Bairut: Dar al-Fiikr), hal.6.
} 
meyakini serta mengamalkan tuntunan Allah SWT, melainkan banyaknya dalil adalah penguat dan pengokoh keyakinan dan kemantapan hati mereka.

Salah satu dalil yang akan kami kemukakan kali ini adalah sebuah hadits yang cantumkan oleh Imam al-Nawawi dalam kitab Riyadh al-Shalihin yaitu:

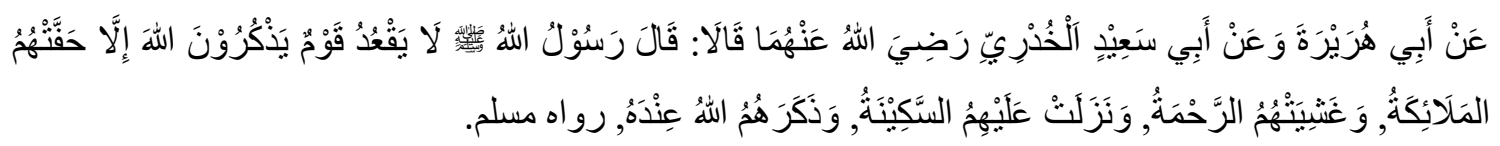

Artinya: Abu Hurairah ra. dan Abu Sa'id ra. keduanya berkata bahwa Rasulullah saw bersabda, "Tidaklah duduk suatu kaum untuk berdzikir kepada Allah swt. Melainkan para Malaikat mengelilingi mereka, rahmat meliputi mereka, dan ketenangan turun kepada mereka, serta Allah menyebut mereka di hadapan Malaikat yang ada di sisiNya." (h.r. Muslim) ${ }^{9}$

Juga mari kita renungkan sebuah hadits yang di kutip dalam kitab Riyadh al-Shalihin:

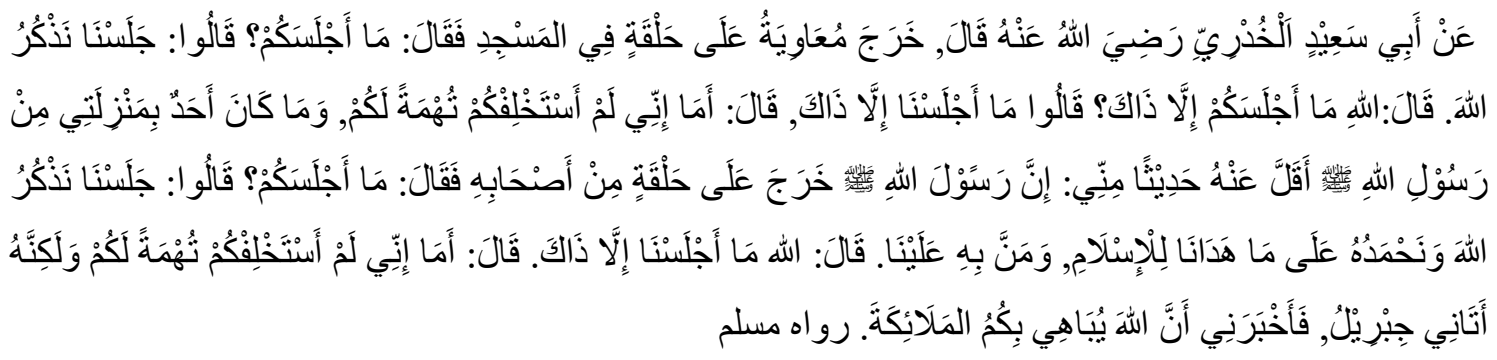

Artinya: "Abu Sa'id al-Khudri r.a. berkata, "Muawiyah keluar menuju halaqah(sekumpulan orang) yang ada di dalam masjid," lalu ia bertanya, "Apa yang mendorong kalian duduk di masjid?" Mereka menjawab, "Kami duduk mengingat Allah" Ia bertanya, "apakah hanya semata karena Allah itu yang mendorong kalian duduk?” Mereka menjawab, "Tidak ada yang mendorong kami untuk duduk melainkan hanya itu." Lalu ia berkata, "Ketahuilah! Aku meminta kalian untuk bersumpah, bukan karena aku tidak percaya kepada kalian, dan tidak ada seorangpun yang sama denganku kedudukannya di sisi Rasulullah saw yang lebih sedikit meriwayatkan hadits beliau daripada aku. Sesungguhnya Rasulullah saw pernah keluar untuk menemui sekumpulan sahabatnya." Lalu beliau bertanya, "Apa yang mendorong kalian duduk di sini?" Mereka menjawab, "Kami duduk untuk berdzikir mengingat Allah dan memuji Allah

\footnotetext{
${ }^{9}$ DR. Musthafa Said Khin, Syarah dan terjemah Riyadus Shalihin, (Jakarta: al-I'tishom), hal.591.
} 
atas nikmat hidayah yang telah membawa kami kepada Islam serta menganugerahkannya kepada kami." Beliau bertanya, "Demi Allah, apakah hanya itu yang mendorong kalian duduk?" Mereka menjawab, "Demi Allah tidak ada yang mendorong kami duduk melainkan itu!" Beliau bersabda, "Ketahuilah! Aku meminta kalian untuk bersumpah, bukan karena aku tidak percaya kepada kalian, akan tetapi Jibril datang kepadaku dan memberitahukan kepadaku bahwa Allah membanggakan kalian dihadapan para Malaikat.” (h.r. Muslim) ${ }^{\mathbf{1 0}}$

Dua hadits diatas adalah salah satu diantara dalil-dalil yang menjelaskan tentang keutamaan berdzikir secara bersama-sama. Dan kami anggap dalil diatas sangatlah kuat untuk dijadikan sebuah pijakan dalam hal ini.

Jika anda berkata; "Memang hadits diatas adalah dalil bagi keutamaan berdzikir secara bersama-sama. Lalu bagaimana dengan shalawat? Apakah ada dalil yang menjelaskan tentang pembacaan shalawat secara bersama-sama?".

Jawabannya , langkah pertama bagi kita adalah kita harus tahu bahwa shalawat juga bisa di kategorikan dzikir kepada Allah, kenapa demikian? Karena di dalam shalawat pasti kita menyebut Allah SWT, entah dengan ungkapan يا رب صل , اللهم صل, atau dengan ungkapan صلى اله dan lain-lain. Jadi bisa di simpulkan bahwa shalawat adalah bagian dari dzikir kepada Allah swt.

Namun jika dibutuhkan dalil dalam hal itu, maka Imam al-Nawawi menyebutkan sebuah hadits dalam kitab Riyadh al-Shalihin yaitu:

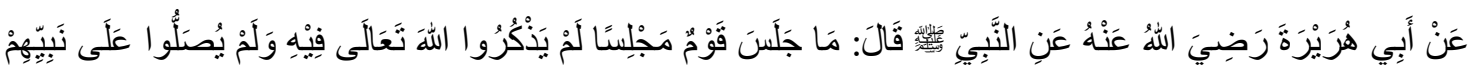

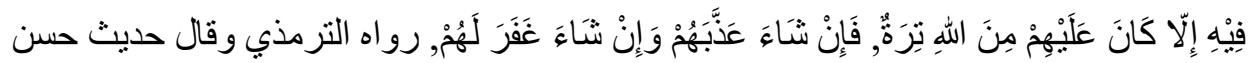

Artinya: "Abu Hurairah berkata bahwa Rasulullah saw. Bersabda, "Tidaklah duduk suatu kaum di sebuah majlis yang tidak berdzikir kepada Allah dan tidak bershalawat di dalam majlis itu melainkan pasti ada atas mereka kekurangan dari Allah, jika Allah berkehendak maka Allah akan mengadzab mereka, dan jika Allah berkehendak maka Allah akan mengampuni mereka." (h.r. al-Tirmidzi) ${ }^{\mathbf{1 1}}$

\footnotetext{
${ }^{10}$ DR. Musthafa Said Khin, Syarah dan terjemah Riyadus Shalihin, (Jakarta: al-I'tishom), hal 593.juz 2.

${ }^{11}$ DR. Musthafa Said Khin, Syarah dan terjemah Riyadus Shalihin, (Jakarta: al-I'tishom), hal. 87.juz.2
} 
Sudah kami sebutkan dalil-dalil yang menjelaskan tentang keutamaan berdzikir secara berjamaah, namun menurut pengamatan kami, tujuan inti dari diadakannya kegiatan shalawat Nariyah ini jika di tinjau dari segi berdzikir secara berjamaah, bukan hanya sebatas ingin memperoleh keutamaan itu, walaupun para kiyai-kiyai meyakini bahwa meraih keutamaan itu adalah sebuah anugerah yang indah dari Allah SWT, dan para kiyai-kiyai juga mengharapkannya, namun yang di jadikan prioritas utama adalah sebagaimana yang telah difirmankan oleh Allah swt,

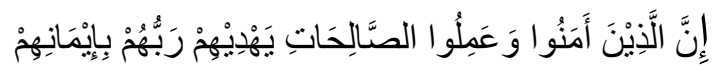

Artinya: "Sesungguhnya orang-orang yang beriman dan beramal shaleh tuhan mereka menuntun mereka dengan keimanan mereka”.

Dan juga sabda Rasulullah saw,

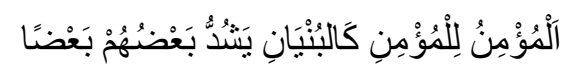

Artinya: "Orang Mukmin kepada orang Mukmin yang lain itu laksana sebuah bangunan yang saling munguatkan satu bagian kepada bagian yang lain" 12

Coba kita renungkan kira-kira apakah yang telah memudar dalam dunia Islam sehingga menjadi sebuah problem yang tidak terpecahkan pada dewasa ini? Menurut kami jawaban yang paling pas adalah "JIWA PERSAUDARAAN" betapa tidak, kebanyakan dari kita sesama Muslim saling mencari kesalahan dan kekurangan yang lain, baik individual ataupun golongan, hanya demi sebuah reputasi. Lihatlah merekamereka yang menangis, terluka, bahkan kehilangan keluarga dan orang-orang yang mereka sayangi, bukankah mereka juga ingin dan berhak untuk bahagia? Bukankah mereka juga berkeinginan hanya sekedar untuk tersenyum bersama keluarga dan orang yang mereka sayangi? Namun semua itu seakan telah sirna dari pandangan bahkan khayalan mereka. Tahukah anda, apa yang telah merenggut senyum dari wajah-wajah mereka? Krisis jiwa persaudaraanlah yang menyebabkan semua itu, lihatlah! Mereka rela saling meninggikan suara bahkan mengangkat senjata hanya demi memperebutkan "saya yang benar dan kamu yang salah" seakan-akan mereka terlupa atau pura-pura

\footnotetext{
${ }^{12}$ DR. Musthafa Said Khin, Syarah dan terjemah Riyadus Shalihin, (Jakarta: al-I'tishom), hal. 294. Juz.1.
} 
melupakan persaudaraan yang telah dibangun oleh Rasulullah selaras dengan sabda beliau, "Orang Muslim adalah saudara bagi orang Muslim yang lain”.

Simpelnya yang paling dharapkan dari pembacaan shalawat Nariyah ini, jika di tinjau dari sudut pandang berdzikir secara berjamaah adalah keinginan para kiyai-kiyai seperti KH Ahmad Sufyan dan KH Muhammad bin Imam untuk mengajak umat agar supaya bersama-sama kepada Allah SWT, seraya menggalang persatuan dan keeratan hubungan sesama orang yang beriman, sehingga saling melengkapi satu sama lain, dan sama-sama di tuntun oleh Allah dengan keimanan yang ada di dalam dada.

\section{Shalawat sebagai pertahanan}

KH Zaki Abdulllah cucu KH Ahmad Sufyan bercerita, bahwa KH Ahmad Sufyan sering berdawuh dalam bahasa Madura: Mara pajhelen shalawat ariya, shalawat riya dedhi pertahanan (ayo hidupkan shalawat ini, shalawat ini menjadi pertahanan) diketika mendengar KH Ahmad Sufyan berdawuh demikian, KH Zaki masih belum faham apa yang di maksud oleh KH Ahmad Sufyan dengan kata "pertahanan" pertahanan apa? Dan pertahanan dari apa?

Detak detik kehidupan terus berjalan, demikian pula waktu terus berlalu Sehingga KH Zaki berdawuh: sekarang saya baru faham bahwa yang dimaksud dengan "pertahanan" yaitu pertahanan rohani, jasmani kita, pertahanan agama kita serta pertahanan daerah kita agar terhindar dari marabahaya dzahir dan bathin.

Allah SWT berfirman:

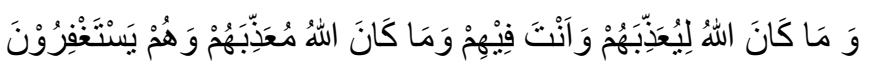

Artinya: Dan Allah sekali-kali tidak akan mengadzab mereka, sedang kamu berada di antara mereka. dan tidaklah (pula) Allah akan mengazab mereka, sedang mereka meminta ampun.

Syekh Ismail Haqqi al-Burusawi menafsiri ayat "وانت فيهم" (apabila kamu nabi Muhammad, berada di tengah-tengah mereka) bahwa sesungguhnya apabila Allah menurunkan adzab maka adzab itu akan merata, dan Allah tidak mengadzab suatu kaum kecuali setelah keluarnya utusan Allah bersama orang-orang Mukmin dari kaum 
tersebut, dan hal itu merupakan bentuk keutamaan yang dikaruniakan Allah kepada para Rasulullah yang telah diutus oleh Allah sebagai rahmat bagi semesta Alam. Sedangkan rahmat dan adzab merupakan dua hal yang saling bertolak belakang, sehingga dikatakan bahwa Rasulullah adalah keamanan yang agung selama beliau hidup atau sunnahsunnah beliau kekal di tengah umat, ayat tersebut adalah dalil atas kemuliaan Rasulullah di sisi Allah sehingga Allah menjadikan beliau sebab bagi keamanan umat, dan ayat tersebut menunjukan bahwa sesungguhnya Allah mengangkat adzab dari sebuah kaum karena kebersamaan mereka dengan orang-orang yang shalih dan bertaqwa. ${ }^{13}$

Maka dari itu pembacaan shalawat Nariyah dihidupkan di tengah-tengah masyarakat salah satu tujuannya agar tuntunan Rasulullah hidup dan mengakar kuat di tengah-tengah masyarakat, sehingga menjadi pertahanan rohani dan jasmani baik secara individu ataupun semua masyarakat secara umum, pertahanan dari apa? Pertahanan dari segala marabahaya, marabahaya dhzahir lebih-lebih marabahaya yang melanda bathin seperti ragu kepada Allah, sifat iri dengki, sombong dan sifat sifat yang buruk lainnya, sehingga kita semua mempunyai hubungan yang baik dengan Allah, senang dalam beribadah menghambakan diri kepada Allah dan mempunyai hubungan yang baik dengan manusia.

\section{Bertawassul dengan kemuliaan Kanjeng Nabi Muhammad SAW}

Sebagaimana telah kita ketahui di dalam shalawat Nariyah sangat kental dengan Tawassul dengan kemuliaan kanjeng nabi Muhammad. Tawassul dalam dunia ini seakan telah menjadi perdebatan yang tak berujung, namun seyogyanya para ulama telah menjelaskan secara rinci tentang kebolehan bahkan keutamaan tawassul itu sendiri, dan tak perlu lagi untuk diperdebatkan, yang hanya akan mengasilkan permusuhan dan perpecahan wal 'iyadzu billah.

Dalam penjelasan kali ini kami akan mengemukakan tentang hadits-hadits pijakan para ulama tentang kebolehan bahkan keutamaan tawassul. Namun sebelum itu kita harus mengetahui terlebih dahulu bagaimana pemahaman tawassul yang tepat.

Sayyid Muhammad bin Alwi Al-Maliki berdawuh dalam kitab Mafahim Yajibu An Tushahah: Orang-orang banyak yang keliru di dalam memahami haqiqat tawassul

\footnotetext{
${ }^{13}$ Syekh Ismail Haqqi al-Burusawi, Tafsir Ruh al-Bayan, (Bairut: Dar al-Fikr, 2006) hal.1596-1597. Juz. 3.
} 
oleh karena itu, kami akan menjelaskan tentang pemahaman tawassul yang benar menurut pemahaman kami, sebelum itu kami harus menjelaskan beberapa point penting ini:

1. Sesungguhnya tawassul adalah salah satu jalan untuk berdoa, dan salah satu pintu untuk bertawajjuh kepada Allah, maka dari itu tujuan asli dari tawassul itu adalah Allah, sedangkan sesuatu yang di jadikan tawassul hanyalah perantara untuk mendekatkan diri kepada Allah, dan barangsiapa yang berkeyakinan lebih dari itu maka dia telah melakukan kesyirikan.

2. Sesungguhnya orang yang bertawassul tidaklah bertawassul dengan perantara melainkan karena kecintaannya kepada perantara tersebut, dan dia berkeyakinan bahwa Allah mencintai perantara itu, jika tidak demikian (tidak cinta, dan tidak dicintai Allah) maka orang tersebut tidak akan bertawassul dengan sesuatu yang tidak dicintai Alah.

3. Sesungguhnya orang yang bertawassul apabila berkeyakinan bahwa sesuatu yang dijadikan tawassul dapat bermanfaat dan memudharatkan dengan dirinya sendiri tanpa pemberian dan pertolongan Allah, maka dia sungguh telah melakukan kesyirikan.

4. Sesungguhnya tawasssul bukanlah hal yang wajib dan pasti, dan Ijabah Allah tidak menunggu hal tersebut, bahkan aslinya adalah doa kepada Allah secara mutlak sebagaimana yang telah difirmankan oleh Allah

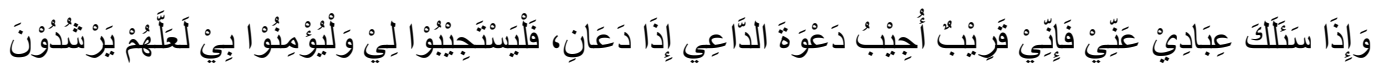

Artinya: dan apabila hamba-hamba-Ku bertanya kepadamu tentang Aku, Maka (jawablah), bahwasanya aku adalah dekat. aku mengabulkan permohonan orang yang berdoa apabila ia memohon kepada-Ku, Maka hendaklah mereka itu memenuhi (segala perintah-Ku) dan hendaklah mereka beriman kepada-Ku, agar mereka selalu berada dalam kebenaran.

Dan dalam firman Allah 


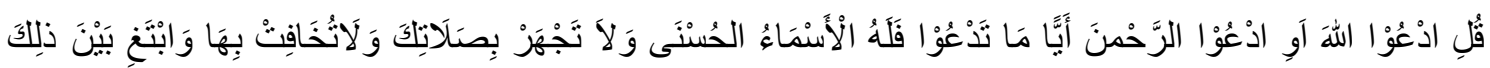

Artinya; Katakanlah: "Serulah Allah atau serulah Ar-Rahman. dengan nama yang mana saja kamu seru, Dia mempunyai Al asmaaul husna (nama-nama yang terbaik) dan janganlah kamu mengeraskan suaramu dalam shalatmu dan janganlah pula merendahkannya dan carilah jalan tengah di antara kedua itu". ${ }^{14}$

Jika ada orang yang berkata, kami tidak mempermasalahkan tawassul dengan perantara amal shalih karena kami telah meyakini akan kebolehan bertawassul dengan menggunakan perantara amal shalih sebagaimana sebuah hadits yang mengisahkan tiga orang laki-laki yang terjebak dalam gua dan Allah menyelamatkan mereka dengan sebab bertawassul dengan amal kebaikan mereka. Namun yang kami permasalahkan adakah dalil yang menjelaskan tentang kebolehan bertawassul dengan perantara manusia dan lain-lain?

Sayyid Muhammad bin Alwi Al-Maliki berdawuh: Allah SWT telah berfirman:

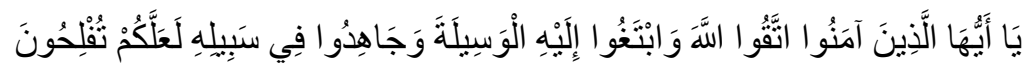

Artinya: Hai orang-orang yang beriman, bertakwalah kepada Allah dan carilah jalan yang mendekatkan diri kepada-Nya, dan berjihadlah pada jalan-Nya, supaya kamu mendapat keberuntungan.

Yang dimaksud dengan Al-wasilah adalah segala sesuatu yang dijadikan sebab oleh Allah untuk memperoleh pangkat dan kedekatan di sisi-Nya, dan sebagai perantara untuk memenuhi kebutuhan-kebutuhan kepada Allah, pada intinya Al-wasilah harus mempunyai kemuliaan disisi Mutawassal ilaih (Allah).

\footnotetext{
${ }^{14}$ DR. Sayyid Muhammad bin Alwi al-Maliki, Mafahim Yajib An Tushahah, (Bairut: Dar al-Kotob Islamiya,2011) hal.118-119.
} 
Lafadz Al-wasilah bersifat umum sebagaimana yang telah anda lihat, dan meliputi terhadap bertawassul dengan dzat-dzat yang mulia seperti para nabi dan orangorang yang shalih baik sewaktu beliau-beliau hidup ataupun sudah wafat. ${ }^{15}$

Berikut kami akan mencantumkan sekelumit hadits-hadits tentang tawassul:

a. Tawassul dengan kemuliaan kanjeng nabi semasa hidup dan setelah kewafatan beliau.

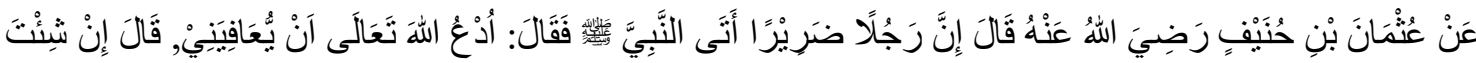

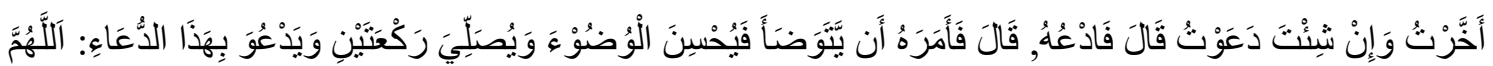

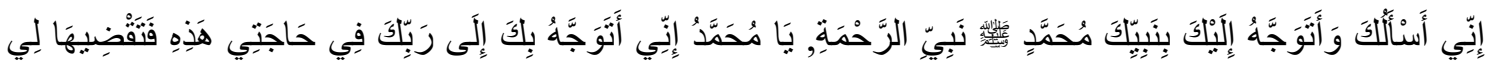

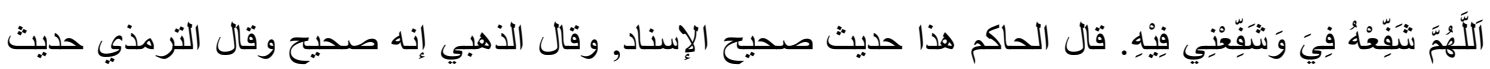
حسن صحيح Artinya: Dari Utsman bin Hunaif ra dia berkata "Sesungguhnya orang laki-laki buta datang kepada nabi kemudian berkata: berdoalah kepada Allah agar menyembuhkanku, kemudian Rasulullah bersabda: Jika kamu mau saya akan menunda doa itu, namun jika kamu mau aku akan berdoa. Maka laki-laki itu berkata: Doakanlah! Maka Rasulullah memerintahkannya untuk berwudhu' dengan menyempurnakan wudhu'nya kemudian shalat dua rakaat dan berdoa dengan doa ini: Ya Allah aku memohon kepada-Mu dan menghadap kepada-Mu dengan nabi-Mu Muhammad SAW nabi kasih sayang, wahai nabi Muhammad aku menghadap bersamamu kepada tuhanmu dalam kebutuhanku ini maka kabulkanlah untukku Ya Allah jadikanlah beliau sebagai pemberi syafaat bagiku, dan jadikan aku penghatur syafaat untuk beliau. Al-Hakim berkata hadits ini adalah hadits dengan sanad yang shahih, Al-dzahabi berkata hadits tersebut adalah hadits shahih, Al-tirmidzi berkata hadits ini adalah hadits hasan shahih. ${ }^{16}$

\footnotetext{
${ }^{15}$ Ibid, hal.120-121.

${ }^{16}$ Ibid, hal.131.
} 
b. Tawassul nabi dengan haq para orang-orang yang meminta kepada Allah

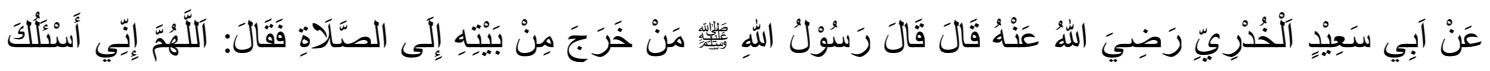

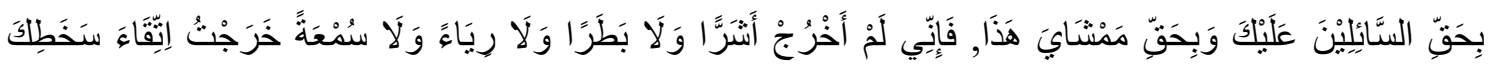

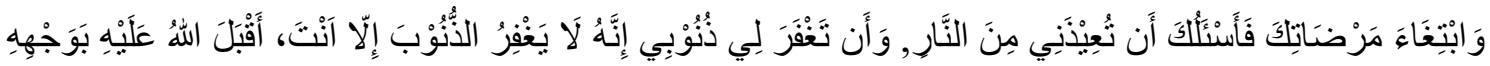

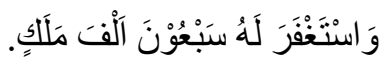
قال الحفيظ ابن حجر هذا حديث حسن أخرجه أحمد و ابن خزيمة في كتاب التوحيد

Artinya: Dari Abu Sa'id Al-khudri ra dia berkata Rasulullah SAW bersabda: Barangsiapa yang keluar dari rumahnya untuk mengerjakan shalat kemudian berdoa: $Y a$ Allah aku meminta kepada-Mu dengan haq orang-orang yang meminta kepada-Mu dan dengan haq perjalananku ini, sesungguhnya aku tidak keluar untuk keburukan, tidak pula untuk kesombongan, riya' dan sum'ah melainkan kau keluar karena takut terhadap murka-Mu serta mengharap keridlaan-Mu maka aku meminta kepada-Mu agar engkau melindungiku dari api neraka dan mengampuni dosa-dosaku karena sesungguhnya tidak ada yang mengampuni dosa-dosa kecuali engkau, maka Allah akan mengahadap kepada orang tersebut dengan wajahnya dan tujupuluh ribu Malaikat memintakan ampunan untuknya. ${ }^{17}$

c. Tawassul dengan Nabi diketika sakit dan sulit

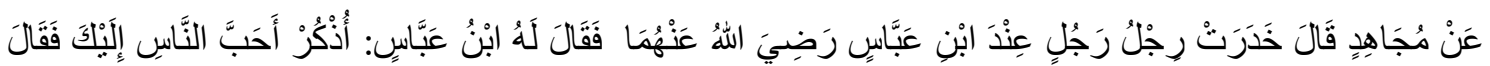

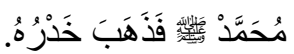

Artinya: Dari Mujahid, dia berkata: kaki seorang laki-laki mengalami kebas (hilang rasa dan tidak dapat bergerak) di sisi Ibnu Abbas ra, kemudian Ibnu Abbas berkata kepadanya sebutlah orang yang paling kamu cintai! Lalu laki-laki tersebut berkata Muhammad SAW maka hilanglah rasa kebas dari kakinya. ${ }^{18}$

$>$ Tawassul dengan makam Nabi atas petunjuk Sayyidah Aisyah

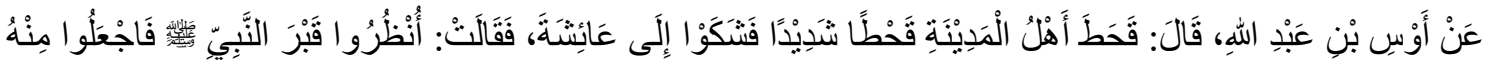

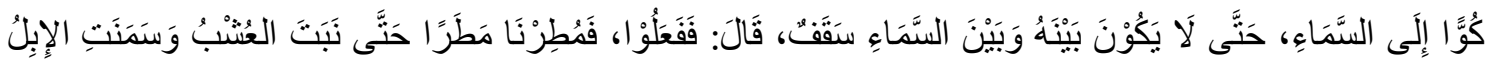

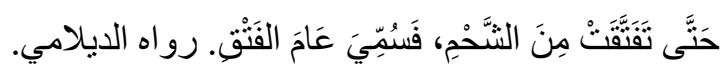

${ }^{17}$ Ibid, hal.147.

${ }^{18} \mathrm{Ibid}$, hal.153. 
Artinya: Dari Aus bin Abdillah dia berkata: Penduduk Madinah mengalami paceklik hebat. Kemudian mereka mengadu kepada Aisyah. Lalu dia berkata: "Pandanglah makam Nabi dan buatlah lubang dari tempat itu menghadap ke atas hingga tidak ada penghalang antara makam dan langit." Aus bin Abdillah berkata: "Lalu mereka melaksankan perintah Aisyah. Kemudian hujan turun kepada kami sehingga rumput tumbuh dan unta menjadi gemuk karena banyak lemak. Maka tahun itu disebut Aam al-Fatq (Tahun Gemuk) ${ }^{19}$

d. Tawassul dengan selain Nabi

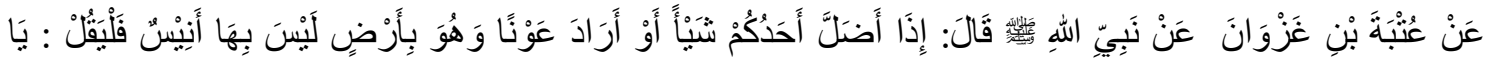

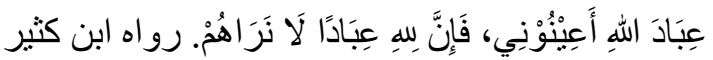

Artinya: Dari Utbah bin Ghazwan, dari Nabi saw beliau berkata: Apabila di antara kamu sekalian kehilangan sesuatu, atau menginginkan pertolongan pada saat dia berada di tempat yang tidak ada seorangpun, maka hendaklah dia berkata: "Hai hamba-hamba Allah tolonglah aku". Karena sesungguhnya Allah mempunyai hamba-hamba yang tidak terlihat oleh kita. ${ }^{20}$

Demikianlah sebagian kecil dalil-dalil tentang tawassul kepada Allah dengan perantara yang dicintai dan dimuliakan oleh Allah, dan kami meyakini bahwa tawassul adalah sebuah amal yang tidak bertentangan dengan syari'at dalam kata lain, tawassul bukanlah perkara bid'ah.

para pembaca yang budiman terdapat sebuah kisah yang sangat menyentuh dalam masalah tawassul ini, dan kami kira sangatlah elok untuk dicantumkan dalam catatan yang singkat ini. Mari kita perhatikan Imam al-Hafidz al-Syaikh Imad al-Din Ibnu Katsir beliau berkata: Sebuah golongan menyebutkan sebuah kisah yang Masyhur diantara mereka Abu Manshur al-Shabagh dalam kitab al-Syamail diceritakan dari Utbi dia berkata: Pada suatu saat aku duduk di sisi makam Nabi SAW, lalu datanglah seorang A'rabi lalu berkata: Salam yang penuh kedamaian untukmu wahai Rasulullah, aku mendengar Allah berfirman dalam Al-qur'an:

\footnotetext{
${ }^{19}$ Ibid, hal.148.

${ }^{20}$ Ibid, hal.153.
} 


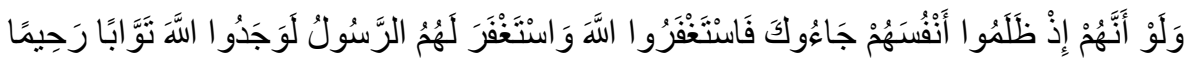

Artinya: Sesungguhnya Jikalau mereka ketika Menganiaya dirinya datang kepadamu, lalu memohon ampun kepada Allah, dan Rasulpun memohonkan ampun untuk mereka, tentulah mereka mendapati Allah Maha Penerima taubat lagi Maha Penyayang. Dan sekarang aku datang kepadamu untuk meminta ampun atas segala dosa-dosaku dan memohon syafaatmu kepada tuhanku. kemudian A'rabi itu membaca syair:

Wahai manusia terbaik dimakamkan dalam bumi jasadnya

\section{Maka harumlah lembah dan bukit karena keharumannya}

Jiwaku menjadi tebusan kubur yang engkau penghuninya

\section{Didalamnya terdapat pribadi yang suci, pemurah lagi mulia}

al-Utbi melanjutkan ceritanya, kemudian dia meninggalkan makam nabi dan aku pun tertidur dalam tidurku aku melihat Rasulullah seraya bersabda: Temuilah A'rabi itu dan sampaikanlah kabar gembira kepadanya bahwa Allah telah mengampuninya. ${ }^{21}$

Subhanallah para pembaca yang budiman sangat jelas bagi kita sekalian, betapa Rasulullah tidak meninggalkan para pecinta dalam ketersesatan di dunia ini, walaupun raganya tak pernah bertemu dengan beliau bahkan jasadnya dipisahkan oleh alam namun ruh dan kecintaan tak kan terpisah oleh apapun bahkan sampai ke akhirat kelak manusia akan dikumpulkan dengan yang dicintai.

\section{D.Kesimpulan}

Para saudara yang dirahmati Allah, Menurut pemahaman dan keyakinan kami, kegiatan shalawat Nariyah secara berjamaah ataupun perindividu adalah sesuatu yang baik dan tidak bertentangan dengan syari'at Islam sebagaimana dalil-dalil yang telah kami kemukakan di atas, bahkan dengan diadakannya pembacaan shalawat Nariyah ini kita memohon dan mengharap kepada Allah agar senantiasa menambahkan keimanan dan kecintaan kita kepada Allah dan Rasulullah dengan kata kongkritnya membangun agama di mulai dari dalam diri kita sendiri.

\footnotetext{
${ }^{21}$ Ibid, hal.157.
} 
Namun terlepas dari semua itu, apabila terdapat pemahaman yang tidak sepaham dengan apa yang telah kami sampaikan, kami memakluminya dan tidak ada niatan bagi kami untuk menyinggung apalagi membuka gerbang perdebatan yang hanya akan mendatangkan permusuhan dan murka Allah SWT wal iyadzu billah.

Kami hanya ingin memperkokoh kemantapan dalam hati dan berkata "INILAH JALAN YANG TELAH DICONTOHKAN OLEH GURU-GURU KAMI”.

\section{E.Penutup}

Para pembaca yang budiman, demikianlah sekelumit catatan yang dapat kami kemukakan. Semoga bermanfaat dan apabila terdapat kekeliruan dari apa yang telah kami kemukakan mohon diluruskan dengan niat dan cara yang baik.

Senantiasa kita mengaharap kepada Allah semoga kita bersama akan mendapatkan tambahan keimanan dan kecintaan kepada Allah dan Rasulullah serta orang-orang yang shalih sehingga kelak kita semua akan dikumpulkan bersama beliaubeliau.

Semoga kita senantiasa dibimbing oleh Allah Amin. 


\section{Daftar Pustaka}

Burusawi (al), Ismail Haqqi. Tafsir Ruh al-Bayan. (Bairut, Dar al-Fikr, 2006).

Nawawi (al), Abu Zakariya. Riyadh al-Shalihin. (Indonesia, al-Haramain ).

Shiddiqi (al), Muhammad bin Ilan. Dalil al-Falihin li thuruqi Riyadh al-Shalihin.

(Kairo, Dar al-Taufiqiyah).

DR. Said Khin. Syarah dan Terjemah Riyadh al-Shalihin. (Jakarta, al-I’tishom, 2015).

Nabhani (al), Yusuf bin Ismail. Afdhal al-Shalawat Ala Sayyid al-Sadat. (Jakarta,

Indonesia, Dar al-Kutub al-Islamiyah, 2004).

Nawawi (al), Abu Zakariya. al-Adzkar al-Nawawi. (Bairut, Dar al-Fikr, 2016).

Absyihi (al), Muhammad bin Syu'aib. Fadlu al-Shalah Ala al-Nabiyyi al-Mukhtar.

(Bairut, Libanon, Dar al-Kutub al-Ilmiyah).

Maliki (al), Muhammad bin Alwi. Mafahim Yajib An-Tushahhah. (Bairut, Libanon, Dar al-Kutub al-Ilmiyah, 2011).

Mubarakfuri (al), Shafiyyur Rahman. al-Rahiq al-Makhtum. (Jakarta, Pustaka alKautsar).

Dimyati Badruzzaman, Ahmad. Zikir Berjamaah Sunnah Atau Bid'ah. (Jakarta, Republika). 
